\title{
Dexmedetomidine: The Anesthetic as an Antiarrythmic
}

\section{Minati Choudhury*}

Cardiothoracic Sciences Centre, All India Institute of Medical Sciences, New Delhi, India

\begin{abstract}
Cardiac arrhythmias are significant cause of morbidity and mortality during perioperative period as well as in critically ill patients in intensive care units (ICU). These rhythm disturbances that may be well tolerated in normal heart can cause significant hemodynamic instability in patients with a congenital or acquired heart problem. Management of these arrhythmias possess a challenge because currently available antiarrhythmic have several disadvantages. Dexmedetomidine (DEX) is a highly selective alpha-2 adrenergic receptor agonist with sympatholytic, sedative, amnesic and analgesic properties. Growing evidences has been suggested the potential therapeutic application of DEX in the management of cardiac rhythm disturbances. This work has an intention to review and update the application of DEX for management of various cardiac arrhythmias. A comprehensive review of pharmacology, mechanism of antiarrhythmic action and side effects of this drug is presented.
\end{abstract}

Keywords: Dexmedetomidine; Cardiac arrhythmias; Perioperative period; Intensive care unit

\section{Introduction}

Cardiac arrhythmias are significant cause of morbidity and mortality during perioperative period as well as in critically ill patients in intensive care units (ICU) $[1,2]$. These rhythm disturbances that may be well tolerated in normal heart can cause significant hemodynamic instability in patients with a congenital or acquired heart problem [3]. Management of these arrhythmias present more of a challenge due to several reasons. First of all, currently available antiarrythmics can be ineffective and poorly tolerated in these scenarios. Lidocaine, beta blockers, adenosine, amiodarone and magnesium are the commonly used antiarrythmics have their own merits and demerits. Lidocaine is only effective in ventricular tacyarrhythmias [2]. Betablockers though effective in various type of arrhythmias, can cause bradycardia, hypotension and conduction block. These drugs again cannot be administered in patients having the history of bronchial asthma. Amiodarone is an excellent agent for ventricular arrhythmias; have off level use in supraventricular arrhythmias. It has a very long half life and is a less commonly used drug in perioperative scenario. Adenosine is an amazing drug for the rapid treatment of supraventricular tachycardias in which AV node is a part of re entry pathways. However, it has an ultra short half life and a proarrhythmic for the chemical cardioversion of re-entrant SVT. The use of adenosine is again associated with an unpredictable duration of bradycardia and asystole, even though it can be tolerated in most of the cases. Electrolytes like magnesium are useful only for treatment of arrhythmias due to hypomagnesemia [4].

The $\alpha_{2}$-adrenoreceptor agonist dexmedetomidine (DEX) is highly selective and potent drug with sympatholytic, sedative, amnesic and analgesic properties, which has been initially described as a useful and safe adjunct in anaesthetists' armamentarium [5]. Growing evidence has been, suggested the potential therapeutic application of DEX in the management of cardiac rhythm disturbances. This report aims to update the brief pharmacology and review the role of DEX as an antiarrythmic agent. A Med Line search of literature on the use of DEX to prevent and treat cardiac arrhythmia was conducted and 29 reports are added to this review.

\section{History and Pharmacology}

The early clinical use of $\alpha_{2}$-adrenoreceptor agonist was in 1960 . The first substance of this group clonidine while used as a nasal decongestant produced severe cardiovascular depression. Gradually, it gained acceptance for the management of blood pressure as well as an adjunct to other agents in anesthesia practice. DEX is the stereoisomer of medetomidine subsequently gained massive importance as a sedative agent during perioperative period. This is because, in addition to its well-known anaesthetic properties, it has shown an inhibitory effect on supraventricular and ventricular arrhythmias [5].

The $a_{2}$-adrenoreceptors have been implicated in a variety of physiological functions. They are transmembrane receptors composed of excitable G-proteins, and consists of three $\alpha_{2}$ adrenoreceptors $\alpha_{2}$ a, $\alpha_{2}-b$ and $\alpha_{2}-c$ which binds $\alpha_{2}$ agonists and antagonists with similar affinities. Alpha -adrenoreceptor stimulation alleviates cardiovascular and electrophysiological changes caused by $\alpha_{1}$ stimulation and attenuates the L-type $\mathrm{Ca}^{2+}$ current. The $\alpha_{2}$-adrenoreceptors are distributed in brain stem, peripheral vasculature and presynaptic nervous terminal as an autosupressive receptor. The receptor suppressers its own adrenaline release from the terminal reticulum to the effectors including brain stem system, vasculature, and the heart achieving sedation, analgesia, decreased blood pressure and bradycardia.

DEX is the pharmacologically active dextroanatiomer of metedomidine and chemically described as (+)-4-(S)-[1-(2-3 dimethylphenyl) ethyl]-1 H-imidazole monochloride. It has a molecular weight of 236.7. It is water soluble with a $\mathrm{pH}$ range of 4.5 7 and $\mathrm{pKa}$ of 7.1. This drug follows linear or zero order kinetics. The onset of action after intravenous administration is approximately 15 minutes. The peak concentration is achieved within 60 minutes of continuous infusion. The drug is also absorbed systemically through the transdermal, oral or intramuscular routes. The protein binding of DEX is $94 \%$ and it remains constant despite varied plasma concentration of the drug. A significant decrease in the bound fraction has been noted in patients with hepatic dysfunction. DEX has a rapid distribution

*Corresponding author: Minati Choudhury, Cardiothoracic Sciences Centre, All India Institute of Medical Sciences, New Delhi, India, Fax: +911126588641; E-mail: minatichoudhury2002@yahoo.co.in

Received June 09, 2015; Accepted August 24, 2015; Published August 28, 2015

Citation: Choudhury M (2015) Dexmedetomidine: The Anesthetic as an Antiarrythmic. Cardiol Pharmacol 4: 153. doi:10.4172/2329-6607.1000153

Copyright: (C) 2015 Choudhury M. This is an open-access article distributed under the terms of the Creative Commons Attribution License, which permits unrestricted use, distribution, and reproduction in any medium, provided the original author and source are credited. 
phase with a steady state volume distribution of $118 \mathrm{~L}$, distribution half life of 6 minutes, elimination half life of between 2.0 to 2.5 hours and clearance of $39 \mathrm{Lhr}^{-1}$. The total plasma concentration of DEX is age independent, thus a similar rate of infusion can be used in children and adults to achieve a steady state plasma concentration. However, a dose reduction is needed in patients above 65 years. This drug is extensively metabolized in the liver through glucuronide conjugation and biotransformation by the cytochrome P450 enzyme system. There are no known active toxic metabolites. However, hepatic clearance may be decreased by as much as $50 \%$ of normal with severe liver disease. The metabolites are eliminated to the extent of $95 \%$ in the urine and $4 \%$ in the faeces [6]. The various pharmacological effects of DEX are mediated by specific $\alpha_{2}$ adrenoreceptor subtype. Agonism at the $\alpha_{2}$ a receptor promotes sedation, hypnosis, analgesia, sympatholysis, neuroprotection and inhibition of insulin secretion.Agonism at $a_{2-} b$ receptor suppresses shivering centrally, promotes analgesia at spinal cord sites, and induces vasoconstriction at peripheral arteries. Action at $\alpha_{2} c$ receptor is associated with modulation of cognition activity and regulation of epinephrine outflow from adrenal medulla.

Though DEX has very minimal side effects, it can not be overlooked. It causes a biphasic dose dependent cardiovascular response after initial administration. A bolus dose of $1 \mu \mathrm{gmkg}^{-1}$ results in an initial increase in blood pressure and reflex bradycardia. This initial response lasts for 5-10 minutes and is followed by a minimal decrease in blood pressure due to inhibition of central sympathetic flow $[7,8]$. The incidence of these effects has been reported to be as high as $40 \%$ in healthy patients. These temporary cardiovascular side effects have been managed with atropine, ephedrine and volume infusion. Caution should be taken in patients where sympatholytic action of DEX prove detrimental eg in patients with left ventricular dysfunction, volume depleted/ vasoconstricted patients or patients who have heart block. There are reports of cardiac arrest with the use of this drug [9,10]. Despite profound sedative effect DEX has a wide safety margin on respiratory function. However episodes of hypoxia have been noted by some authors with the use of this drug $[11,12]$.Overdose may cause first of second degree heart block. These effects may be most pronounced in patients with decreased autonomic response such as elderly, diabetic patients with chronic hypertension.

\section{Effect of DEX on Cardiac Electrophysiology}

DEX modifies the cardiac autonomic state, not only by cardiac adrenaline release but also by activating the release of acetylcholine. The various cardiovascular responses of DEX regulated by $\alpha_{2}$ adrenoreceptors, varies depending upon their locations. Stimulation of the receptors in the brain stem and spinal cord inhibit neuronal firing, which leads to hypotension and bradycardia. In a prospective randomized study by Hammer et al, 12 children underwent standard ablation of supraventricular accessory pathways followed by the measurement of the electrophysiological variables. DEX was administered thereafter, at a dose of $1 \mu \mathrm{gmkg}^{-1}$ for $10 \mathrm{~min}$ followed by $0.7 \mu \mathrm{gmkg}^{-1} \mathrm{hr}^{-1}$. Post DEX administration, the sinus node function was depressed as evidenced by an approximately $38 \%$ increase in the corrected sinus node recovery time $(\mathrm{p}<0.01)$. There was a $30 \%(\mathrm{p}<0.01)$ increased in sinus cycle length. The atrioventricular (AV) nodal properties were also prolonged as evidenced by an increased in PR interval, Wenckebach cycle length and AV nodal refractory period. There was a slight increased in effective refractory period from $220 \pm$ 22 to $230 \pm 19 \mathrm{~ms}(\mathrm{p}=0.06)$ and QTc interval from $394 \pm 9$ to $424 \pm 9 \mathrm{~ms}$ $(\mathrm{p}<0.01)$ [13]. Chrysotomou et al in a prospective observational study noted the effect of DEX on surface electrocardiogram of 76 children who underwent surgery for congenital heart disease. The DEX group received $1 \mu \mathrm{gmkg}^{-1}$ loading dose of the drug followed by a maintenance infusion of $1 \mu \mathrm{gmkg}^{-1} \mathrm{hr}^{-1}$ for 15 hours. The administration of DEX was followed by a decrease in heart rate (HR) from $140 \pm 22$ to $116 \pm 23$ bpm $(\mathrm{p}<0.002)$. The PR interval increased from $115 \pm 28$ to $122 \pm 29$ $\mathrm{ms}(\mathrm{p}=0.01)$, the QRS interval decreased from $84 \pm 21$ to $80 \pm 21 \mathrm{~ms}$ $(\mathrm{p}=0.02)$ and the QTc interval did not reveal any change [14]. In the author's opinion, the electrophysiologic changes that appear during peak level of DEX can dissipate with time.

\section{Mechanism of Antiarrythmic Effect}

The precise mechanism for its antiarrhythmic properties of DEX has not been fully understood. The latest purposed mechanism of a decreased in HR in response to DEX appears to be mediated through enhancement of vagal neuronal activity at nucleus tractus solitarius, the point at which vagal sensory input terminates $[15,16]$. This effect was first demonstrated by Hayashi et al who tested the arrythmogenic threshold for epinephrine during halothane anesthesia in the presence of DEX. They observed that DEX increases the arrhythmogenic threshold for epinephrine in a dose dependent manner during halothane anaesthesia [15]. They also demonstrated that Atipamizole, a central $\alpha_{2}$-antagonist that crosses the blood brain barrier, block the antiarrhythmic effect of DEX. However, L-659,066, a peripheral $\alpha_{2}$ antagonist that does not penetrate the blood brain barrier, has no effect on the anti arrhythmic effect of DEX. Thus the antiarrhythmic effect of this drug is mediated at least in part by stimulation of central $\alpha_{2}$ adrenoreceptor. Administration of DEX results in activation of central presynaptic $\alpha_{2}$-a adrenoreceptors in the dorsal motor neurons of the vagus (DMNV) and nucleus ambiguous (NA) leading to the activation of $\mathrm{G}$ proteins. This causes a decrease in adenylate cyclase activity, which subsequently decreases cyclic adenosine monophosphate (cAMP) and finally a reduction in $\mathrm{L}$ type of $\mathrm{Ca}^{++}$current, which in turn leads to prolong repolarization and prolonged refractory period [17]. The parasympathetic antiarrythmic effect is more pronounced when cAMP is already stimulated and increased by either endogenous or exogenous catecholamines.

Recent studies have shown that activation of central imidazoline type I receptors has been implicated in the prevention of ventricular arrhythmias. DEX contains an imidazole ring and involves in the activation of these receptors, indicating another probable mechanism of its antiarrhythmic action [5]. This drug also possesses central sympatholytic properties through presynaptic activation of $\alpha_{2}$ adrenergic receptors in the sympathetic nerve endings and subsequent negative feedback to the synaptic vesicle, resulting in inhibition in norepinephrine release [18].This action is of particular importance because DEX may be used with the intention of attenuating the hypercatecholaminergic state seen after cardiopulmonary bypass and there by decrease the incidence of catecholamine driven tachycardia of hemodynamic significance (Figure 1).

Few initial clinical experience in adult population revealed its potential efficacy in terminating inappropriate tachycardia during off pump coronary artery bypass grafting (CABG) and in preemptively decreasing the incidence of postoperative hyperadrenergic hemodynamic response $[19,20]$. However, the sample size in Jalonen $J$ et al's report was too small to evaluate reliably the events such as bradycardia the need of cardiac pacing. Continuous infusion of DEX for termination of tachycardia can also increase the propensity towards hypotension [19]. The major clinical study that reveals the antiarrhythmic properties of DEX has been narrated brief in Table 1. In a DEX pre-treated experimental rat model, a significantly increased in the time to first arrhythmia was demonstrated by Hanci V and colleague 


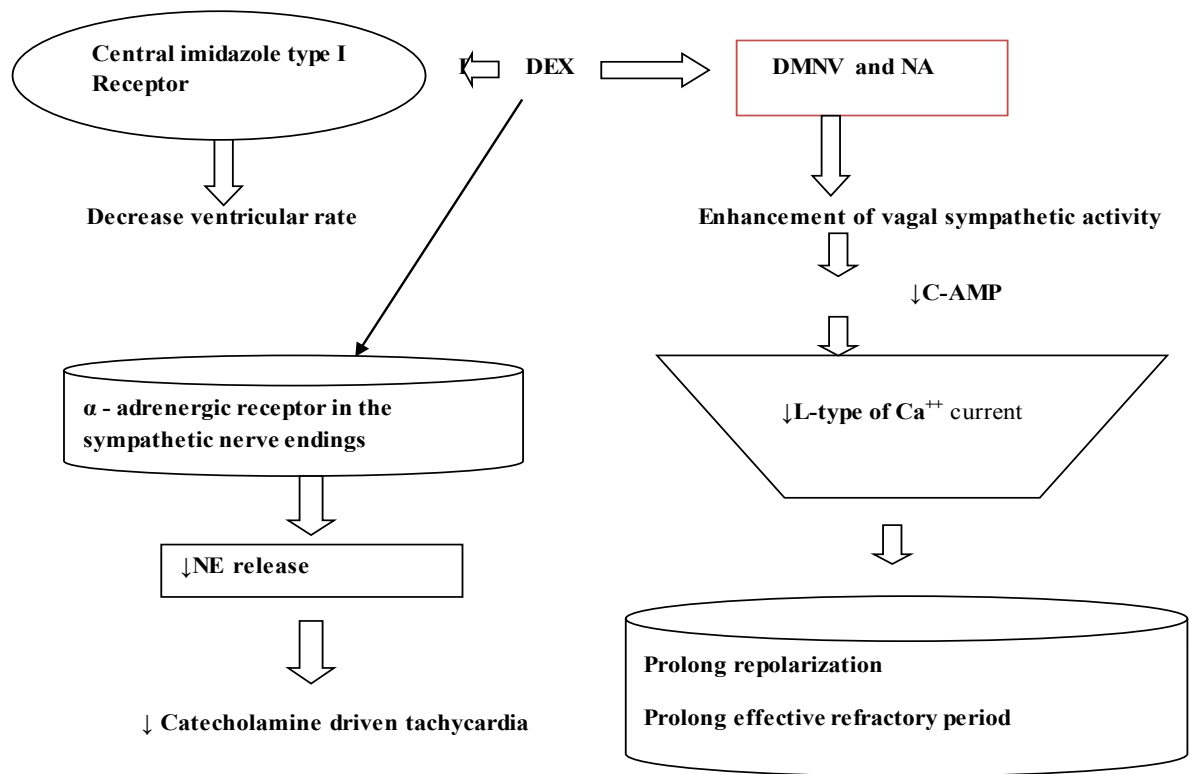

Figure 1: A schematic presentation of the possible mechanisms involved to mediate the antiarrhythmic action of DEX: DMNV and NA, Dorsal Motor Neurons of the Vagus and Nucleus Ambiguous; C-AMP, Cyclic Adenosine Monophosphate; NE, Norepinephrine.

\begin{tabular}{|c|c|c|}
\hline Authors, year and references & Sample size, patient population and arrhythmias & Outcome /Inference \\
\hline Jalonen J et al. (1997) [19] & $\begin{array}{l}\text { Eighty adult patients scheduled for routine coronary artery bypass } \\
\text { grafting. DEX was used for the prevention of perioperative sinus } \\
\text { tachycardia }\end{array}$ & $\begin{array}{l}\text { DEX decreased both the incidence of sinus tachycardia as } \\
\text { well as the need for use of } \beta \text {-adrenergic agonists }\end{array}$ \\
\hline Chrysotomou and collegue (2008) [22] & $\begin{array}{l}\text { Retrospective nonrandomized non-controlled study. } \\
\text { DEX was administered for the treatment of post-operative } \\
\text { tachyarrhythmias in } 14 \text { pediatric cardiac surgical patients. }\end{array}$ & $\begin{array}{l}\text { DEX has a potential therapeutic role in the acute phase of } \\
\text { various atrial and junctional tachyarrhythmias for either HR } \\
\text { control or conversion to NSR with minimal side effects. }\end{array}$ \\
\hline Herr et al. (2003) [23] & $\begin{array}{l}\text { Prospective cohort study which involved } 295 \text { patients undergoing } \\
\text { CABG. } \\
\text { DEX based sedation was compared with propofol based sedation for } \\
\text { adverse event study. }\end{array}$ & $\begin{array}{l}\text { No episode of ventricular tachycardia occurred in DEX } \\
\text { sedated patients compared with a } 5 \% \text { incidence of the } \\
\text { same among the patients sedated with propofol. } \\
\text { There was a decrease need of } \beta \text {-adrenergic antagonists } \\
\text { in DEX group. }\end{array}$ \\
\hline Chrysotomou C et al. (2011) [24] & $\begin{array}{l}\text { Prospective control trial involving pediatric cardiac surgical patients } \\
\text { ( } 32 \text { patients treated with DEX and compared with } 20 \text { controls). } \\
\text { The mean DEX dose was } 0.74 \pm 0.4 \mu \mathrm{gmgg}^{-1} \text {. }\end{array}$ & $\begin{array}{l}\text { Significant reduction in the incidence of VT ( } 0 \% \text { vs. } \\
25 \%) \text { and SVT ( } 6 \% \text { vs. } 25 \%) \text { in the DEX treated group in } \\
\text { comparison to the controls. } \\
\text { Transient heart block was observed in two patients from } \\
\text { DEX group and in one from controls. }\end{array}$ \\
\hline Chrysotomou C et al. (2013) [24] & $\begin{array}{l}\text { Retrospective case series ( } 15 \text { patients). } \\
\text { A comparison of DEX with adenosine was done for termination of } \\
\text { SVT episodes. }\end{array}$ & $\begin{array}{l}\text { DEX was more effective }(96 \%) \text { in termination of SVT } \\
\text { episodes than adenosine }(63 \%)\end{array}$ \\
\hline Turan A and colleague (2014) [29] & $\begin{array}{l}\text { Multivariate logistic regression analysis, in } 17776 \text { patients, including } \\
765 \text { post cardiac surgical patients who received DEX for ICU } \\
\text { sedation. } \\
\text { The incidence of atrial arrhythmias was reviewed. }\end{array}$ & $\begin{array}{l}\text { The patients who was given DEX had a lower risk of atrial } \\
\text { tachyarrhythmias (OR } 0.74,95 \% \mathrm{Cl}: 0.60,91 ; \mathrm{p}=0.004) \\
\text { without any significant adverse outcome. }\end{array}$ \\
\hline \multirow[t]{2}{*}{ Rajput RS et al. (2014) [30] } & $\begin{array}{l}\text { Prospective randomized study for evaluation of the effect of DEX } \\
\text { on JET ( } 220 \text { paediatric cardiac surgical patients who underwent } \\
\text { corrective surgery for TOF). } \\
\text { The treatment group received an initial bolus dose of DEX ( } 0.5 \\
\left.\mu \mathrm{gmkg}^{-1}\right) \text { over } 10 \text { minutes followed by a continuous infusion of } 0.5 \\
\mu \mathrm{gmkg}^{-1} \mathrm{hr}^{-1} \text { till } 8^{\text {th }} \text { postoperative hour. }\end{array}$ & $\begin{array}{l}\text { The incidence of JET was higher in control group ( } 20 \% \text { vs. } \\
9.09 \%), p=0.022) \text { and it occurred early }(0.14 \pm 0.527 \mathrm{~h} \text { vs. } \\
0.31 \pm 1.29 \mathrm{~h}, \mathrm{p}=0.042) \text {; as well as stayed for a longer time } \\
\text { in comparison to DEX group. }\end{array}$ \\
\hline & $\begin{array}{l}\text { Prospective observational study. } \\
\text { Out of } 1593 \text { surgical procedures for congenital heart disease DEX } \\
\text { was administered in the immediate postoperative period after } 468 \\
(29 \%) \text { of the surgical procedure. } \\
\text { The association of DEX and subsequent arrhythmia development } \\
\text { was studied. }\end{array}$ & $\begin{array}{l}\text { DEX exposure in the postoperative period was not } \\
\text { associated with a clinically significant difference in the } \\
\text { incidence of tachyarrhythmias after congenital cardiac } \\
\text { surgery; however it may be associated with increase odds } \\
\text { of bradyarrhythmias. }\end{array}$ \\
\hline
\end{tabular}

Table 1: Studies showing the possible use of Dexmedetomidine as an antiarrhythmic in different settings: DEX, Dexmedetomidine; CABG, Coronary Artery Bypass Grafting; VT, Ventricular Tachycardia; SVT, Supraventricular Tachycardia; JET, Junctional Ectopic Tachycardia; TOF, Tetralogy of Fallot. 
[21]. Chrysotomou and colleague in a retrospective nonrandomized non-controlled study administered DEX for the treatment of tachyarrhythmia [junctional ectopic tachycardia (JET), atrial ectopic tachycardia (AET), re-entry type supraventricular tachycardia (reSVT), atrial flutter (AF) or junctional accelerated rhythm (JAR)] in 14 postoperative congenital cardiac surgical patients [22]. The drug was used as a primary treatment in nine $(64 \%)$ and rescue in $5(36 \%)$ patients. The goals of DEX therapy were conversion to normal sinus rhythm (NSR) within 3 minutes for SVT and within 2 hour for all other tachyarrhythmias or a decrease in HR to a level that can cause an improvement in hemodynamic condition. In $93 \%$ of patients the primary outcome with rhythm and / or heart controlled was achieved. JET rate was decrease from $197 \pm 22$ to $165 \pm 17 \mathrm{bpm}$ within $67 \pm 75$ minutes of DEX administration in all the six patients who had JET. All four patients with Re-SVT had resolution of their tachyarrhythmias. Three of converted to NSR and one to JAR. One patient with AET (220$270 \mathrm{bpm}$ ) responded well with decreasing HR to $120 \mathrm{bpm}$ within 35 minutes and to NSR in $85 \mathrm{~min}$. However, one patient with AF failed to respond. In two patients with JAR, HR decreased from $158 \pm 11$ to $129 \pm 16 \mathrm{bpm}$. Four patients faced adverse events; out of which 3 had hypotension that was resolved with volume supplementation and one had complete heart block which was again not related with DEX. The authors suggested that DEX may have a potential therapeutic role in the acute phase of atrial and junctional tachyarrhythmias for either HR control or conversion to NSR. The major drawback of this study was, there was no control group with a more frequently used drug (Amiodarone) to treat arrhythmia. The authors also could not able to distinguish the possible synergistic effect between amiodarone DEX from an actual DEX effect.

The beneficial effect of DEX as a negative chronotropic agent was further observed by Herr and colleague in a prospective trial while comparing DEX based sedation with that of Propofol based sedation in patients undergoing CABG surgery. DEX was administered at a dose of $1 \mu^{g k^{-1}}$ during sternal closure followed by an infusion of 0.2-0.7 $\mu_{\mathrm{gm} \mathrm{kg}}{ }^{-1} \mathrm{hr}^{-1}$ to maintain a Ramsay sedation score of 3 or higher. The other group received a propofol based sedation regimen during mechanical ventilation. While evaluating the adverse events, the authors observed that no episode of ventricular tachycardia occurred among the DEX sedated group compared with a 5\% incidence among the patients sedated with Propofol $(p=0.007)$ [23]. In addition, the patients who received DEX based sedation had a decreased need for $\beta$ adrenergic antagonists. Chrysostomou $\mathrm{C}$ et al. in the year 2011 again used DEX during the perioperative period ( $38 \pm 4 \mathrm{hrs}$ ) in 32 pediatric cardiac surgical patients to prevent the incidence of postoperative tachyarrhythmia. The drug was used at a mean dose of $0.76 \pm 04$ $\mu \mathrm{gmkg}^{-1} \mathrm{hr}^{-1}$. They included a control group of 20 patients who did not receive DEX. The overall incidence of postoperative arrhythmia was $6 \%$ in DEX group compared to $50 \%$ in controls. The incidence of VT ( $0 \%$ vs. $25 \%, \mathrm{p}=0.05)$ and the SVT ( $6 \%$ vs. $25 \%)$ was significantly less in DEX group compared with the controls. Control group had a higher incidence of sinus tachycardia requiring more nicardipine (13 \pm 5 vs. $\left.2 \pm 1 \mu \mathrm{gm}^{-1} \mathrm{~kg}^{-1}, \mathrm{p}=0.02\right)$ and more fentanyl ( $39 \pm 8$ vs. $19 \pm$ $\left.3 \mu \mathrm{gm}^{-1} \mathrm{~kg}, \mathrm{p}=0.005\right)$. Two patients from DEX group and one from controls had transient complete heart block. The authors concluded that perioperative use of DEX is associated with significantly decreased incidence of ventricular and supraventricular tachyarrhythmias, without any significant adverse effects [24] In this report, the author's observation period was only 72 hours and thus they might have missed arrhythmias that occurred afterwards. Again, this study was a non randomised single- institution methodology, which can not establish direct causal relationship with certainty.
The same investigators again analyzed a retrospective case series of patients who received DEX for SVT. They compared the SVT episodes terminated with DEX with the episodes that terminated with adenosine. Twenty seven doses of DEX were given to fifteen patients with a mean dose of $0.7 \pm 0.3 \mu \mathrm{gm}^{-1} \mathrm{~kg}$ for a total of 27 episodes of SVT. Successful termination occurred in 26 episodes $(96 \%)$ at a median time of 30 seconds. Five patients received 27 doses of adenosine for 27 episodes of SVT with a successful cardio version in 17 episodes $(63 \%, p=0.0017)$. The authors concluded that DEX has a novel antiarrythmic property, for the acute termination of re entrant SVT with a more favourable therapeutic profile and less side effect and increased effectiveness when compared with adenosine [25]. The authors used several of the DEX doses in the presence of other antiarrhythmic agents, and thus a synergistic/additive effect is possible. Ohsugi E et al. administered DEX to a 3 year old boy who had refractory SVT (not responding antiarrhythmic and cardio version) after total cavopulmonary connection. Supportive extracorporeal life support was given to maintain the hemodynamics. After administration of DEX the sinus rhythm was returned without any further recurrence of this episode [26]. A significant decrease in the incidence of VTs with DEX infusion $\left(1 \mu \mathrm{gm}^{-1} \mathrm{~kg}^{-1} \mathrm{~min}\right)$ was observed in an animal model who developed this rhythm disturbance with methoxamine and nifekalant pre-treatment (VT s in this animal model was triggered by early depolarization). The authors concluded that DEX may be a therapeutic choice for abnormal repolarization related VTs that are resistant to conventional treatment [27].

Lee C and colleague used DEX at the rate of $0.5 \mu \mathrm{gmkg}^{-1} \mathrm{hr}^{-1}$ as a slow intravenous infusion for over 180 seconds followed by a continuous infusion at a dose of $0.7 \mu \mathrm{gmkg}^{-1} \mathrm{hr}^{-1}$ for the termination of paroxysmal supraventricular tachycardia(PSVT) in a patient who was undergoing thoracic surgery. The PSVT was developed during lung retraction and was non respondent to carotid sinus massage as well as to adenosine ( $6 \mathrm{mg}$ followed by $12 \mathrm{mg}$ according to the standard two stage protocol). The rhythm was returned to normal sinus and blood pressure improved. The authors recommended that DEX may be used as a second line drug, if adenosine used as a first line drug fails in the acute treatment of SVTs [28].

Turan A and colleague conducted a multivariate logistic regression analysis, in 17776 patients, including 765 post cardiac surgical patients who received DEX for ICU sedation. The incidence of atrial arrhythmias was reviewed. Patients who received postoperative DEX had a lower risk of atrial tachyarrhythmias (OR 0.74, 95\% CI: 0.60, 91; p=0.004) without any significant adverse outcome [29]. The major limitation of this study was its observational design. The study also does not include the exact DEX dose given and the duration of its use.

Rajput RS et al in a prospective randomized study evaluated the effect of DEX on JET. The study comprised of 220 paediatric cardiac surgical patients who underwent corrective surgery for tetralogy of fallout. The treatment group received an initial bolus dose of DEX $\left(0.5 \mu \mathrm{gmkg}^{-1}\right)$ over 10 minutes followed by a continuous infusion of $0.5 \mu \mathrm{gmkg}^{-1} \mathrm{hr}^{-1}$. The infusion was continued throughout operation till the weaning from mechanical ventilation. The control group received a similar amount of normal saline. The duration of the study was till 8 hrs postoperatively. The incidence of JET was higher in control group ( $20 \%$ vs. $9.09 \%), p=0.022)$ and it occurred early ( $0.14 \pm 0.527 \mathrm{~h}$ vs. 0.31 $\pm 1.29 \mathrm{~h}, \mathrm{p}=0.042$ ); as well as stayed for a longer time in comparison to DEX group [30].

Le Riger $\mathrm{M}$ administered DEX at a dose of $3 \mu \mathrm{gm}^{-1} \mathrm{~kg}^{-1} \mathrm{hr}^{-1}$ in a 6 weeks old infant who developed JET following the release of aortic 
cross clamp. The resolution of JET was occurred within 15 minutes of administration of the drug. The authors did not administered adenosine because the patient was still on $\mathrm{CPB}$. The patient was successfully weaned off from CPB without any additional inotropic support [31].

Another group of investigators examined the association between use of DEX in the immediate postoperative period and subsequent arrhythmia development in a trial of 468 patients who underwent congenital heart surgery. The comparison was done with 1125 patients who did not receive the drug and act as a control. Significantly less tachycardia $(29 \%$ vs. $38 \%), \mathrm{p}<0.001)$, tachyarrhythmias receiving intervention $(14 \%$ vs. $23 \%, \mathrm{p}=<0.001)$, bradyarrhythmias $(18 \%$ vs. $22 \%, \mathrm{p}<0.03)$ and bradyarrhythmias receiving intervention $(12 \%$ vs. $16 \%, \mathrm{p}=0.04$ ) was noted in DEX group in comparison with the controls. However, after propensity score matching with 468 controls, the arrhythmia incidence between groups became similar. They exclude controls exposed to DEX at a later time in hospitalization and noted that DEX was associated with a dose dependent increase in the odds of bradyarrhythmias (OR 1.04, 95\% CI 1.01-1.07) and receiving interventions (OR 1.05, 95\% CI 1.01-1.08) [32].

All these evidences suggest that success with DEX to prevent or treat several types of arrhythmias was impressive. The drug seems to be more impressive in the termination of supraventricular arrhythmias and junctional tachycardia. Again the antiarrhythmic effect was achieved within the maximum recommended dose used for sedation, both for adult as well as children. In most of the studies the arrhythmia free time was more than one hour. This is an additional benefit over other antiarrhythmics in the subject that; it maintains hemodynamic stability and decreases the amount of multiple administration of ultra short acting drug like adenosine until a longer acting agent of choice Eg. Digoxin, amiodarone has reached an effective, steady level. DEX can be used as an adjunct to other conventional antiarrhythmics. Being devoid of negative inotropic or pro arrhythmic effects, in contrast to beta- adrenergic blockers and amiodarone; this drug has been proved to be relatively safe in the situation of acute treatment of tachyarrhythmias.

In spite of the definite antiarrhythmic effect of DEX, it is important for the clinician to select the appropriate patient as well as clinical setting for its safe use. Careful haemodynamic monitoring is essential during the administration of this drug for a better dose titration as well as avoidance of haemodynamic adverse events associated with its use. Rapid infusion and large boluses should be avoided in neonates, patients with volume depleted state/hepatic disease/ significant hypoalbuminemia. In spite of several studies to support the antiarrhythmic role of this drug, future prospective trials are needed to define its role in this setting.

\section{Conclusions}

The potent and highly selective $\alpha_{2}$ adrenergic dexmedetomidine not only provides unique type of sedation and analgesia with minimal side effect, but also have a special antiarrhythmic effect. It can be used as an adjunct to other conventional antiarrhythmics. Like many other antiarrhythmics, it does not have any proarrythmic effect, hence can be used relatively safely for acute termination for tachyarrhythmias or its prevention. Despite the presence of good number of evidences to support it as an antiarrhythmic; it is important for the clinicians to select appropriate patients and clinical settings for its safe use. Large doses or rapid intravenous infusion should be used with caution in patients with significant ventricular dysfunction or who have a risk for AV block. Moreover it should be also used with caution in patients already receiving drugs with significant negative chronotropic effect. With these caveats in mind DEX appears to be a useful antiarrythmic agents for the prevention and treatment of arrhythmias especially those of supraventricular in origin.

\section{References}

1. Amar D (2002) Perioperative atrial tachyarrhythmias. Anesthesiology 97: 16181623.

2. Thompson A, Balser J R (2004) Perioperative Cardiac Arrythmias. Br J Anaesth 93:186-194.

3. Pfammatter JP, Bachmann DC, Wagner BP, Pavlovic M, Berdat P, et al. (2001) Early postoperative arrhythmias after open-heart procedures in children with congenital heart disease. Pediatr Crit Care Med 2: 217-222.

4. Bradley D, Creswell LL, Hogue CW Jr, Epstein AE, Prystowsky EN, et al (2005) Pharmacologic prophylaxis: American College of Chest Physicians guidelines for the prevention and management of postoperative atrial fibrillation after cardiac surgery. Chest 128: 39S-47S.

5. Afonso J, Reis F (2012) Dexmedetomidine: Current role in anesthesia and intensive care. Rav Bras Anaesthesiol 62:118-132.

6. Coursin DB, Coursin DB, Maccioli GA (2001) Dexmedetomidine. Curr Opin Crit Care 7: 221-226.

7. Kamibayashi T, Maze M (2000) Clinical use of alpha-2 adrenergic agonists Anesthesiology 93:1343-1349.

8. Penttilä J, Helminen A, Anttila M, Hinkka S, Scheinin H (2004) Cardiovascular and parasympathetic effects of dexmedetomidine in healthy subjects. Can J Physiol Pharmacol 82: 359-362.

9. Ingersoll-Weng E, Manecke GR Jr, Thistlethwaite PA (2004) Dexmedetomidine and cardiac arrest. Anesthesiology 100: 738-739.

10. Videira RL, Ferreira RM (2004) Dexmedetomidine and asystole. Anesthesiology 101: 1479.

11. Ebert TJ, Hall JE, Barney JA, Uhrich TD, Colinco MD (2000) The effects of increasing plasma concentrations of dexmedetomidine in humans. Anesthesiology 93: 382-394.

12. Aho M, Erkola O, Kallio A, Scheinin H, Korttila K (1993) Comparison of dexmedetomidine and midazolam sedation and antagonism of dexmedetomidine with atipamezole. J Clin Anesth 5: 194-203.

13. Hammer GB, Drover DR, Cao H, Jackson E, Williams GD, et al. (2008) The effects of dexmedetomidine on cardiac electrophysiology in children. Anesth Analg 106: 79-83.

14. Chrysostomou C, Komarlu R, Lichtenstein S, Shiderly D, Arora G, et al. (2010) Electrocardiographic effects of dexmedetomidine in patients with congenital heart disease. Intensive Care Med 36: 836-842.

15. Hayashi $Y$, Sumikawa K, Maze M, Yamatodani A, Kamibayashi T, et al (1991) Dexmedetomidine prevents epinephrine induced arrhythmias through stimulation of central alpha 2 adreno-receptors in halothane anesthetized dogs. Anesthesiology 75:113-117.

16. Kamibayashi T, Hayashi Y, Mammoto T, Yamatodani A, Sumikawa K, et al. (1995) Role of the vagus nerve in the antidysrhythmic effect of dexmedetomidine on halothane/epinephrine dysrhythmias in dogs. Anesthesiology 83: 992-999.

17. Parent BA, Munoz R, Shiderly D, Chrysostomou C (2010) Use of dexmedetomidine in sustained ventricular tachycardia. Anaesth Intensive Care 38: 781 .

18. Snapir A, Posti J, Kentala E, Koskenvuo J, Sundell J, et al. (2006) Effects of low and high plasma concentrations of dexmedetomidine on myocardial perfusion and cardiac function in healthy male subjects. Anesthesiology 105: 902-910.

19. Jalonen J, Hynynen M, Kuitunen A, Heikkilä H, Perttilä J, et al. (1997) Dexmedetomidine as an anesthetic adjunct in coronary artery bypass grafting. Anesthesiology 86: 331-345.

20. Ruesch S, Levy JH (2002) Treatment of persistent tachycardia with dexmedetomidine during off-pump cardiac surgery. Anesth Analg 95: 316-318, table of contents.

21. Hanci V, Karakaya K, Yurtlu S, HakimoÄŸlu S, Can M, et al. (2009) Effects of dexmedetomidine pretreatment on bupivacaine cardio-toxicity in rats. Reg Anesth Pain Med 34: 565-568. 
22. Chrysostomou C, Beerman L, Shiderly D, Berry D, Morell VO, et al. (2008) Dexmedetomidine: A novel drug for the treatment of atrial and junctional tachyarrhythmias during the perioperative period for congenital cardiac surgery: A preliminary study. Anesth Analg 107: 1514-1522.

23. Herr DL, Sum-Ping ST, England M (2003) ICU sedation after coronary artery bypass graft surgery: dexmedetomidine-based versus propofol-based sedation regimens. J Cardiothorac Vasc Anesth 17: 576-584.

24. Chrysostomou C, Sanchez -de- Toledo J, Wearden P, Joost EH, Lichtenstein SE, et al. (2011) Perioperative use of dexmedetomidine is associated with decreased incidence of ventricular and supraventricular tachyarrhythmias after congenital cardiac operations. Ann Thorac Surg 92: 964-972.

25. Chrysostomou C, Morell VO, Wearden P, Sanchez-de-Toledo J, Jooste EH, et al. (2013) Dexmedetomidine: Therapeutic use for the termination of reentrant supraventricular tachycardia. Congenit Heart Dis 8: 48-56.

26. Ohsugi E, Nagamine $Y$, Ohtsuka M (2011) The effect of dexmedetomidine in a child with intractable supraventricular tachyarrythmia after total cavopulmonary connection. Masui 60: 493-495.
27. Tsutsuik, Hayami N, Kanishima T, Sugiura A, Mikamo T, et al. (2012) Dexmedetomidine and clonidine inhibit ventricular tachyarrhythmias in a rabbit model of acquired long QT syndrome. Cir J 76 : 2343-2347

28. Lee C, Kim YD, Seo DH, Lee JH, Song YK (2013) Conversion of supraventricular tachycardia to normal sinus rhythm by dexmedetomidine treatment. Korean $\mathrm{J}$ Anesthesiol 65: S123-124.

29. Turan A, Bashour CA, You J, Kirkova Y, Kurz A, et al. (2014) Dexmedetomidine sedation after cardiac surgery decreases atrial arrhythmias. J Clin Anesth 26: 634-642.

30. Rajput RS, Das S, Makhija N, Airan B (2014) Efficacy of dexmedetomidine for the control of junctional ectopic tachycardia after repair of tetralogy of Fallot. Ann Pediatr Cardiol 7: 167-172.

31. LeRiger M, Naguib A, Gallantowicz M, Tobias JD (2012) Dexmedetomidine controls junctional ectopic tachycardia during Tetralogy of Fallot repair in an infant. Ann Card Anaesth 15: 224-228.

32. Shuplock JM, Smith AH, Owen J, Van Driest SL, Marshall M, et al. (2015) Association between perioperative dexmedetomidine and arrhythmias after surgery for congenital heart disease. Circ Arrhythm Electrophysiol 8:643-650. 